\title{
Production and characterization of orange pigment produced by Halophilic bacterium Salinococcus roseus isolated from Abattoir soil
}

\begin{abstract}
There was little information about the nature of orange pigment produced by Salinococcus roseus. Therefore this study aimed to optimize and characterize the orange pigment produced by Salinococcus roseus isolated from abattoir soil. The soil collected from abattoir was screened for isolation and identification of orange pigment-producing bacteria. The resulting orange pigmented colonies were subjected to biochemical and molecular identification. The phylogenetic analysis of bacterial isolate was carried out using MEGA 6 software. Ethanol was used for pigment extraction and extracted pigment was characterized using UV-Visible spectroscopy and Fourier Transformed Infrared (FTIR) spectroscopy. The stability of the pigment was also determined toward $\mathrm{pH}$ and temperature. The sequence analysis of $16 \mathrm{SrDNA}$ of the isolate showed maximum identity of $100 \%$ to Salinococcus roseus. Of various parameters optimized, a temperature of $37 \mathrm{oC}, \mathrm{pH} 7$, nutrient broth, 96 hours incubation and under shaking condition of $100 \mathrm{rpm} / \mathrm{min}$ was found to be optimum for orange pigment production. The UV-Visible spectroscopy at wavelength of $440 \mathrm{~nm}$ showed characteristic corresponds to zeaxanthin. The FTIR spectroscopy revealed the presence of following functional groups $\mathrm{C}-\mathrm{O}-\mathrm{C}\left(900 \mathrm{~cm}^{-1}\right), \mathrm{C}-\mathrm{H}\left(710 \mathrm{~cm}^{-1}\right), \mathrm{C}=\mathrm{O}\left(1430 \mathrm{~cm}^{-1}\right)$, $\mathrm{C}=\mathrm{C}\left(1610 \mathrm{~cm}^{-1}\right)$ and $\mathrm{OH}\left(3380 \mathrm{~cm}^{-1}\right)$ correspond to zeaxanthin. The pigment was found stable at $\mathrm{pH} 13$ and at temperature of $200 \mathrm{oC}$. This indicated its suitability for various industrial applications such as textile industries.
\end{abstract}

Keywords: Abattoir, sequence, zeaxanthin, FTIR, Salinococcus roseus
Volume 6 Issue 6 - 2018

\author{
Hizbullahi M.Usman, ' AA Farouq, ${ }^{2}$ AS Baki, ${ }^{2}$ \\ N Abdulkadir,' G Mustapha' \\ 'Department of Microbiology, Sokoto State University, Nigeria \\ ${ }^{2}$ Department of Microbiology, Usman Danfodiyo University, \\ Nigeria
}

Correspondence: Muhammad Hizbullahi Usman, Department of Microbiology, Sokoto State University, Sokoto State, Nigeria, Tel+2347068053005, Email muhammabhiz04@gmail.com

Received: November 14, 2018 | Published: December 05, 2018

\section{Introduction}

The color determines the acceptance of a product and has paramount influence on human life. Many synthetic colors used in foodstuff, dyestuff, cosmetics and pharmaceutical manufacturing pose various hazardous effects like allergies, tumor, cancer and severe damages to the vital organs. ${ }^{1}$ Moreover, the effluent of synthetic dyes poses series threat to the environment conservation. Consequently, many synthetic colors have been banned due to their toxicological problems. With the increasing awareness about the toxic effects of synthetic colors and consumer safety, there is an increasing interest in the development of colors from natural sources. ${ }^{2}$ Pigments are the chemical substances that absorb the light of visible region. They produced color because of the chromophore, a molecule specific structure which captures the sun energy and causes an excitation of electron from external orbital to higher orbital, where the non-absorbed energy is refracted or reflected to be captured by eye. ${ }^{3}$ As the present trend throughout the world is shifting towards the use of eco-friendly and biodegradable commodities, the demand for natural colorants is increasing day by day. Natural pigments are sourced from ores, insects, plants and microbes. Among microbes, bacteria have immense potential to produced diverse bio-products and one such bio-product is pigments. Biopigments produced from microorganisms are preferred over those from plants because of their stability ${ }^{4}$ and availability for cultivation throughout the year. ${ }^{5}$ Bacterial pigment production is now one of the emerging field of research to demonstrate its potential for various industrial applications. ${ }^{6}$ Most of the bacterial pigment production is still at the R\&D stage. Hence, work on the bacterial pigments should be intensified especially in finding cheap and suitable growth medium which can reduce the cost and increase its applicability for industrial production.

\section{Materials and methods}

\section{Collection of soil samples}

Twenty (20) different types of soil samples were collected within Sokoto State Abattoir. Ten gram $(10 \mathrm{~g})$ of soil samples were collected in the morning around 7:00 am, by excavating the surface at a depth of $1.0 \mathrm{~cm}$ and transferred into sterile container and labeled accordingly. The containers were placed on ice in a cooler and transport to Microbiology Laboratory, Sokoto State University.

\section{Isolation of orange pigment-producing bacteria}

The soil samples collected were serially diluted and plated on nutrient agar and incubated at $35^{\circ} \mathrm{C}$ for 48 hours. Following the incubation only orange colonies were selected and propagated on the same medium to obtained pure cultures used for further studies.

\section{Morphological and biochemical characterization of the isolates}

Gram staining reaction and microscopic studies were performed for the isolate after 48hours incubation. The biochemical tests performed were Simmon's Citrate test, Indole test, Methyl Red (MR), Voges Proskauer (VP), Oxidase and Catalase tests, Coagulase test, Urease test and TSI for Identification according to Bergey's Manual of Determinative Bacteriology. ${ }^{8}$

\section{DNA extraction using boiling method}

For DNA extraction, single colonies growing on solid media were removed with a sterile plastic tip and resuspended in $100 \mu 1$ of sterile molecular grade water in a micro centrifuge tube and vortex for 1 
minute. Then, the washing of the pellet was done with $200 \mu$ of TBE buffer and suspension was incubated at $95^{\circ} \mathrm{C}$ for 20 minutes. After this incubation, another centrifugation at $4{ }^{\circ} \mathrm{C}$ was performed $10000 \mathrm{rpm}$ for $2 \mathrm{~min}$. Following the last centrifugation, supernatant was collected and used for PCR amplifications (Lexopoulou, et al., 2006)

\section{DNA extraction using phenol-chloroform method}

For DNA extraction, single colonies growing on solid media were removed with a sterile plastic tip and resuspended in $100 \mu$ l of sterile molecular grade water in a micro centrifuge tube and vortex for 1 minute. $100 \mu \mathrm{l}$ of chloroform-isoamyl alcohol were added to the suspensions and, after briefly vortexing for 30 second, the mixture was centrifuged at $16.000 \mathrm{xg}$ for $5 \mathrm{~min}$ at $4^{\circ} \mathrm{C} .10 \mu \mathrm{l}$ of the upper aqueous phase were used as a source of DNA template for the PCR applications. The rest of the mixture was stored at $4{ }^{\circ} \mathrm{C}$ until use (Silva and Silva, 2005).

\section{Polymerase chain reaction}

PCR amplification was carried out on DNA using 16SrDNA. All PCR reaction was performed using Thermal Cycler. Each $50 \mathrm{ml}$ reaction mixture contained 25uL Mastermix (50 units/ml Taqnpolymerase, $400 \mathrm{uL}$ moles DNTPs, $3 \mathrm{mM} \mathrm{MgCl}_{2}$ ) $19 \mathrm{uL}$ of ultrapure PCR water, $2 \mathrm{uL}$ of forward primer and $2 \mathrm{uL}$ of DNA template. Amplification was carried out under the following PCR conditions: Initial denaturation at $95^{\circ} \mathrm{C}$ for 5 minutes, 30 circles at $95^{\circ} \mathrm{C}$ for $1 \mathrm{~min}$, an annealing at $55^{\circ} \mathrm{C}$ for $1 \mathrm{~min}$, elongation at $72^{\circ} \mathrm{C}$ for 2 minutes, with final elongation step of $72^{\circ} \mathrm{C}$ for 5 minutes. Successful amplification was confirmed by ethidium bromide fluorescence in $1 \%$ agarose gel.

\section{Agarose gel electrophoresis}

Agarose gel electrophoresis was carried out on extracted DNA to separate the DNA fragments by their size and to visualize the fragments. This is done by weighing $1.0 \mathrm{~g}$ of agarose and dissolved in $100 \mathrm{ml}$ of $1 \mathrm{X}$ TBE buffer and heated in a microwave for $30 \mathrm{sec}$. swirling halfway through. It was allowed to cool and $4 \mathrm{uL}$ of ethidium bromide was added and poured into taped tray. Bubbles were removed with the tip of the comb and the comb was inserted and allowed to set for 20 mins. The tape and comb were then removed and the ladder and samples were loaded after mixing $5 \mathrm{uL}$ of each sample with $2.5 \mathrm{uL}$ loading dye. It was then run at $100 \mathrm{~V}$ for $40 \mathrm{mins}$. and viewed under UV light.

\section{Sequencing analysis of I6SrDNA}

Samples were sequenced after purification. Sequencing was carried out using the same primers for PCR. Analysis of sequences was carried out using Blast search ${ }^{9}$ by aligning sequences obtained with the closest match found in the GenBank, after which phylogenetic analysis was carried out for the blast results.

\section{Optimization studies}

The optimization studies were carried out in accordance to method used by Batt et al. ${ }^{10}$ An affect of growth media (Nutrient broth, lactose broth and Mueller Hinton broth), Incubation period (24, 48, 72 and 96 hours), effect of $\mathrm{pH}(3,4,5,6,7,8,9$ and 10), effect of temperature $\left(25^{\circ} \mathrm{C}, 30^{\circ} \mathrm{C}, 35^{\circ} \mathrm{C}, 40^{\circ} \mathrm{C}\right.$ and $\left.45^{\circ} \mathrm{C}\right)$ and effect of shaking/ static conditions was determined on the bacteria for highest pigment production.

\section{Production and extraction of pigment}

The isolate was grown in Elemlayer flask containing $250 \mathrm{ml}$ nutrient broth at $37^{\circ} \mathrm{C}$ for 72 hours. The observation of orange pigmentation in a broth indicated pigment production. The extraction of pigment was done by centrifuging the culture broth at 4,000 rpm for 15 minutes, the cell pallets were discarded. The orange pigment cells were washed using deionized water and further extracted by addition of $50 \mathrm{ml}$ of ethanol. The extracted orange pigment was then subjected further analysis.

\section{Characterization of orange pigment}

\section{UV-Visible spectroscopy}

The extracted pigments were subjected to UV-visible spectrophotometric analysis. The extracted color was analyzed by scanning in a UV-Visible spectrophotometer for determining the maximum absorbance. The scanning range was selected from 200$800 \mathrm{~nm}$ and absorbance at an interval of $40 \mathrm{~nm}$ was measured. ${ }^{11}$

\section{Fourier transform infrared (FTIR) spectroscopy}

The concentrated orange pigment was subjected to FTIR spectroscopy. This is done by mixing the pigment extract with small amount of $\mathrm{KBr}$. The preparation was then pressed in a sample holder and analyzed by computerized Fourier Transform Infrared Spectroscopy system which generates the transmitting spectra showing the unique chemical bonds and the molecular structure of the sample material. ${ }^{7}$

\section{Results and discussion}

Twenty (20) abattoir soils were screen for isolation of orange pigment bacteria, a total of fifteen bacteria were isolated showing different pigmentation only one bacterium showed orange pigmentation and was used in this study (Table 1). The colonies of the isolate were round, convex, smooth, mucoid and orange. The intensity of the orange pigment color is increasing on prolonged incubation from light to dark orange color. The pigment was produced in colonies but not diffuses when cells were grown on agar media. The physiological and biochemical characterization of bacterial isolates was done to confirm the genus. Based on the morphological and partial biochemical characteristics, isolates was found to be a motile, Gram-negative, rod-shaped bacterium with the orange colonies in nutrient agar which gave a catalase positive reaction as described in Table 2 (Figure 1).

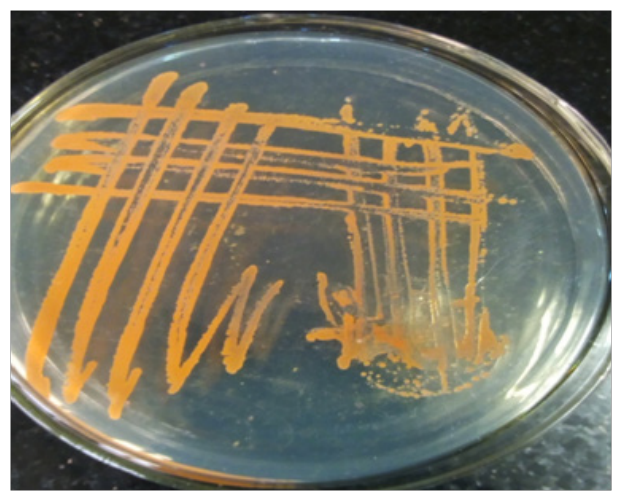

Plate I: Isolated Orange Pigment-Producing Bacteria from Abattoir Soil 


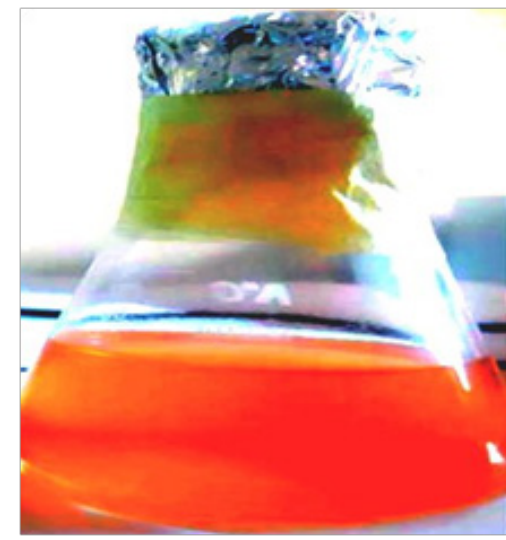

Pate 2: Ethanol Extracted Orange Pigment from Culture of Salinococcus roseus

Table I Pigment-producing bacteria isolated from Abattoir soil

\begin{tabular}{llll}
\hline S/n & Bacterial ID & Colony appearance & $\begin{array}{l}\text { Number of } \\
\text { occurrence }\end{array}$ \\
\hline 1 & SP1 & Blue green pigmentation & 7 \\
2 & SP2 & Yellow Pigmentation & 4 \\
5 & SP7 & Orange pigmentation & 1 \\
7 & SP13 & Yellow green pigmentation & 3 \\
\hline
\end{tabular}

Table 2 Morphological and biochemical characteristics of the isolates

\begin{tabular}{lll}
\hline 1 & Catalase & + \\
2 & Coagulase & - \\
3 & Methyl red test & - \\
4 & Voges proskauer test & - \\
5 & Indole test & - \\
6 & Citrate test & + \\
7 & Urease test & - \\
8 & H2S & - \\
9 & Gas production & + \\
10 & Glucose & + \\
11 & Fructose & - \\
12 & Lactose & - \\
\hline
\end{tabular}

Key: - = Negative $+=$ Positive

The neighbor joining Phylogenetic tree analysis of 16SrRNA sequence of the Salinicoccus sp. with other sequences in the database revealed that, the sequence of the isolate showed $100 \%$ identity to the 16SrDNA gene sequence of Salinococcus roseus (KX000901.1) when the sequence was blasted against NCBI database (Figure 2)(Figure 3).

Salinococcus roseus showed considerable amount of orange pigment production. It was observed that the nutrient broth favors maximum pigment production by Salinococcus roseus with $56 \%$ absorbance, follow by Lactose broth while no pigment production was observed in Mueller (Figure 4). This might be due to availability of some amino acids required for biosynthesis of the pigment which is present in nutrient broth but absent in lactose broth and Mueller Hinton broth. The nutrient broth is a commercially media containing digest of a particular plant or animal protein, which made it available to organisms, as peptides and amino acid to help satisfy the requirements for nitrogen, sulfur, carbon and energy. ${ }^{12}$ Similar results reported by Bhat \& Marar, ${ }^{13}$ who observed that the growth and pigment production were higher when the Salinicoccus roseus (MKJ 997975) was grown in nutrient broth than in lactose broth medium.

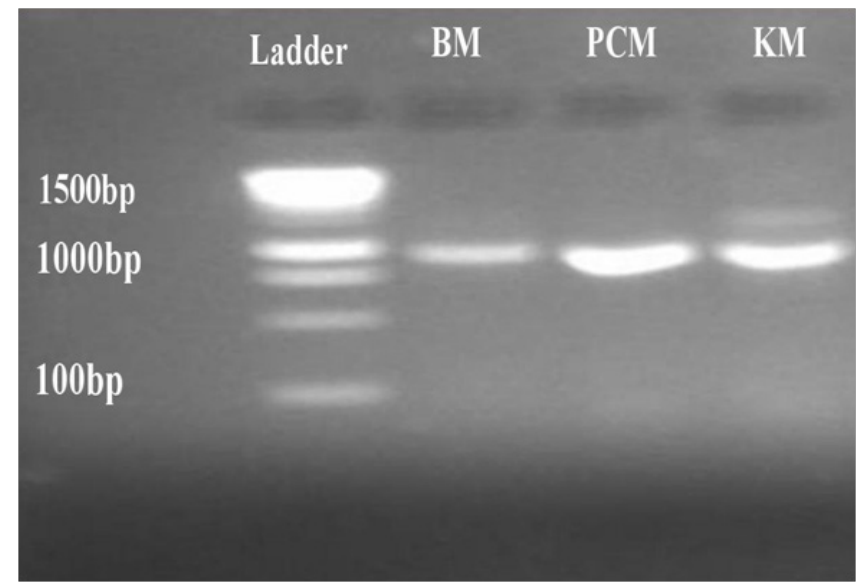

Figure I Agarose gel electrophoresis of the PCR amplified I6SrRNA gene of the isolate.

Key: BM=DNA extraction by boiling Method, PCM=DNA extraction by Phenol-chloroform, KM=DNA extraction using DNA kit method

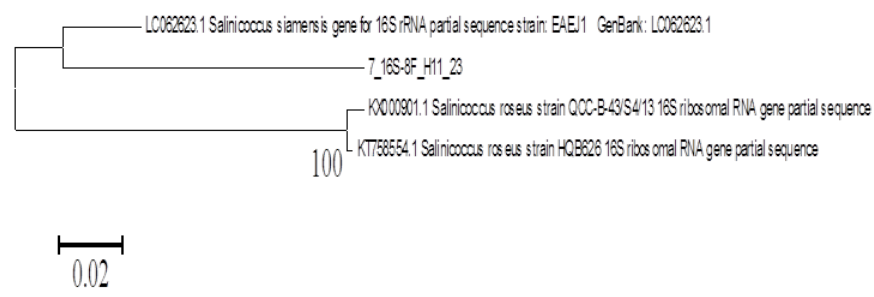

Figure 2 The Phylogenetic analysis by neighbor joining tree of Salinococcus specie isolated from Abattoir soil.

GGGATGCGAGTGCTATACATGCAGTCGAACGCGCGGATCAGGAGCTTGCTCCTGTGACGCGAGTGGCGGA CGGGTGAGTAACACGTAGGCAACCTGCCCATCAGACTGGGATAACCACGGGAAACCGTGGC TAATACCGG ATAATCC TTTTCCACACAGGT GGGAAAGTTGAAAGGCGGTC TTTTGGCTGT CACTGATGGATGGGCCTGC GGCGCAT TAGCT GGTTGGTGGGGTAACGGCCCACCAAGGCGACGATGCGTAGCCGACCTGAGAGGGTGAT CGGCCACACTGGGACTGAGACACGGCCCAGACTCCTACGGGAGGCAGCAGTAGGGAATCTTCCGCAATGG ACGAAAGTCTGACGGAGCAACGCCGCGTGAGTGAAGAAGGGTTTCGGCTCGTAAAACTCTGTTGTCAGGG AAGAACGCCGACGGGAGTAAC TGCCCGTCGGGTGACGGTACCTGACCAGAAAGCCACGGCTAACTACGTG CCAGCAGCCGCGGTAATACGTAGGTGCAAGCGTTATCCGGAATTATTGGGCGTAAAGCGCGCGTAGGCG GTTCGTTAAGTCTGATGTGAAAGCCCCCGGC TCAACCGGGGAGGGT CATTGGAAACTGGCGGACTTGAGT GCAGAAGAGGAGAGTGGAATTCCATGTGTAGCGGTGAAATGCGCAGAGATATGGAGGAACACCAGTGGCG AAGGCGGCTCTCTGGTCTGCAACTGACGCTGAGGTGCGAAAGCGTGGGGAT CAAACAGGAT TAGA TACCC CTGGTAGTCCACGCCGTAAACGATGAGTGCTAAGTGGTAAGGGGGTTTCCGCCCCT TTAGT GCTGCAGCT AACGCAT TAAGCACTCCGCCC TGGGGAGTACGGCCGCAAGGTTGAAACTCAAAGGAATTGACGGGGACCC GCACAAGCGGTGAGCATGTGGTTTAATTTCGAAGCAACGCGAAGACCTTACCAATC TTGACATCC TCTGA CCACCCT GGAGACAGGT TTCCCTTCGGGGCAGAGTGACAGGTGGTGCATGGTGTCGTCAGCTCGTGTCGT GAGATGT TTGGT TAGTTCCGCACGAGCGCACCCTTATCATAGTGCAGCATCAGTGGCACTCTATGGACAC TGCGTGACATCGGAGAAGGTGGGGGA TGACGTCAATCATCATGCCGTTTAAGATGGTTAACACGGTCTCA ATGACGGTACAGCAGCTAAGCGCTAGC

\section{Figure 3 DNA Sequences of Salinococcus roseus.}

The biosynthesis of a pigment is significantly affected by the incubation temperature. ${ }^{14}$ The results of effect of incubation temperature on pigment production (Figure 5) showed that highest pigmentation was observed by Salinococcus roseus $40^{\circ} \mathrm{C}$. The variation of pigment production at different temperature by the Salinococcus roseus might be attributed to enzymes activities during 
growth and pigment production, as highest activities of enzymes occur at optimum temperature. This implies that Salinococcus roseus is mesophilic bacteria requiring optimum temperature between 25 $45^{\circ} \mathrm{C}$.

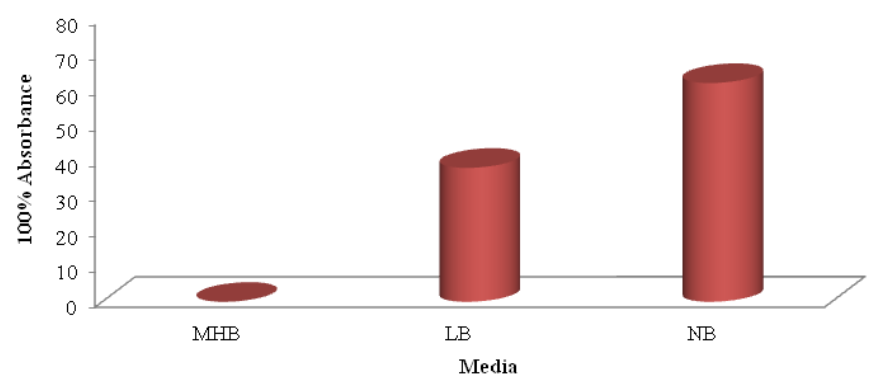

Figure 4 Influence of growth different media on pigment production by Salinococcus roseus.

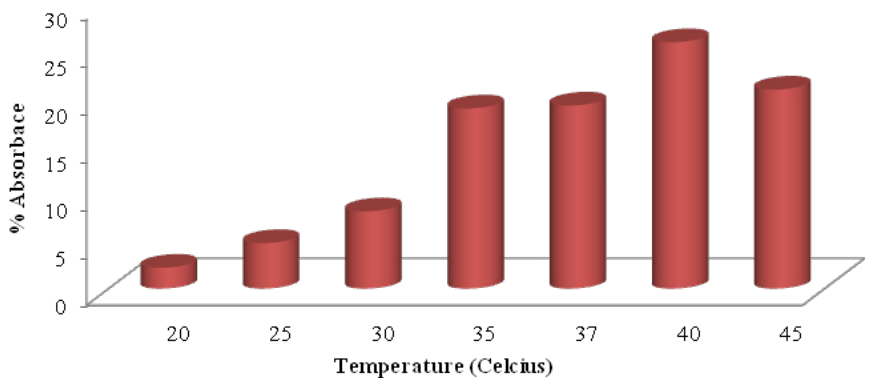

Figure 5 Influence of temperature on pigment production by Salinococcus roseus.

The results of incubation period on pigment production by Salinococcus roseus showed that highest orange pigment production was observed after 96 hours with 38\% absorbance and no pigment was observed after 24 hours incubation (Figure 6). The variation of pigments production by the Salinococcus roseus on incubation time might be attributed to nature of growth of organism, as some bacteria have shorter generation time than others. The increasing pigment production by Salinococcus roseus up till 96 hours might be an indication that the organisms did not reached the peak of its growth. Pigment and other secondary metabolites produced by microorganisms have been shown at stationary phase. ${ }^{15}$ It might also indicate that at this time there is maximum stress in the growth medium which stimulates highest pigment production. This stress could be as a result of nutrient depletion and accumulation of waste products. This implies that as the numbers of days increased, the number of bacteria also increased which would increase the growth and pigments production.

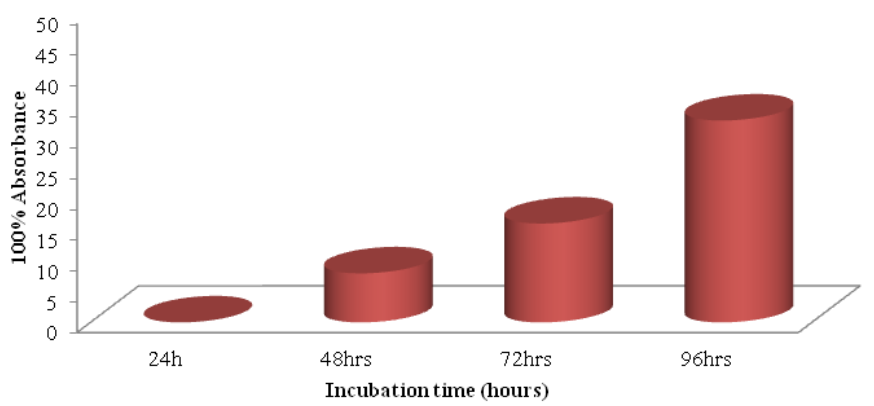

Figure $\mathbf{6}$ Influence of incubation time on pigment production by Salinococcus roseus.
The rate of pigmentation by the Salinococcus roseus was higher around neutrality, at $\mathrm{pH} 7$ the isolate showed highest pigmentation with $30 \%$ absorbance which gradually decline toward alkaline $\mathrm{pH}$ (Figure 7). The low production of pigments by the isolate between $\mathrm{pH} 2-8$ and $\mathrm{pH} 8-10$ might be attributed to enzymes inhibition for the biosynthesis of the pigment at both acidic and alkaline $\mathrm{pH}$. This implies that the bacterial isolates required neutral $\mathrm{pH}$ or somewhere around neutrality for growth and pigment production. The growth and type of pigment production by microorganisms is largely affected by the $\mathrm{pH}$ of the medium in which the microorganisms grow, therefore slight changes in $\mathrm{pH}$ can also alter the rate of growth of microorganisms and pigment production. ${ }^{16}$ Similar work reported by Bhat \& Marar ${ }^{13}$ reported that Salinococcus roseus showed highest pigmentation at $\mathrm{pH}$ 7. The influence of static and shaking condition were determined on pigment production by the Salinococcus roseus. It was observed that the pigmentation was favor under shaking condition while at static condition Salinococcus roseus showed minimum pigmentation (Figure 8). The studied parameters showed that that Salinococcus roseus.

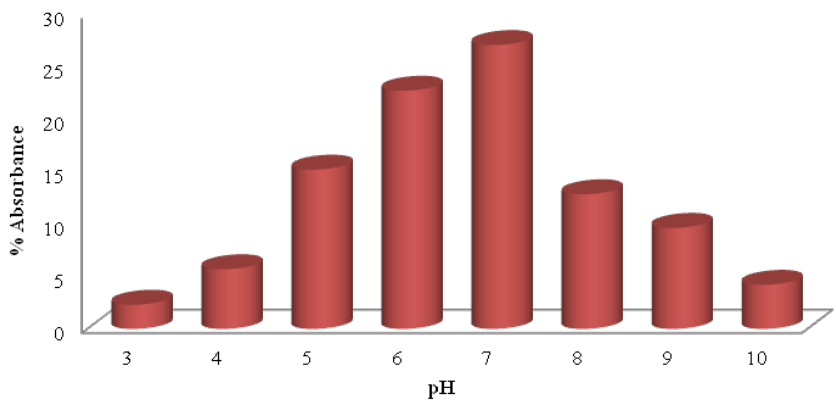

Figure 7 Influence of pH on pigment production by Salinococcus roseus.

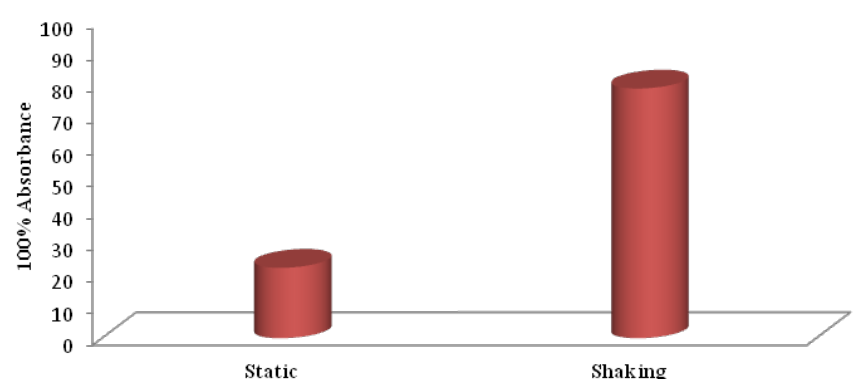

Figure 8 Influence of static/shaking condition on pigment production by Salinococcus roseus.

The UV-Visible results of the extracted pigments was generated at a wavelength region between $200-800 \mathrm{~nm}$. The orange pigment produced by Salinococcus roseus showed highest peak of $450 \mathrm{~nm}$ which gradually declined toward visible region. The highest absorption of orange pigment at $450 \mathrm{~nm}$ might be attributed to conjugated bonds of the pigment. This implies that the highest absorption at $450 \mathrm{~nm}$ is an indication that the orange pigment belong to carotenoid family. Similar results was observed by Bhat $\&$ Marar ${ }^{13}$ who reported that the orange pigment produced by Salincoccus roseus showed highest peak at $450 \mathrm{~nm}$ which is characteristics of carotenoid pigment (Figure 9). The FTIR analysis of orange pigment produced by Salinococcus roseus revealed the following functional groups $\mathrm{C}-\mathrm{O}-\mathrm{C}\left(900 \mathrm{~cm}^{-1}\right)$, $\mathrm{C}-\mathrm{H}\left(710 \mathrm{~cm}^{-1}\right), \mathrm{C}=\mathrm{O}\left(1430 \mathrm{~cm}^{-1}\right), \mathrm{C}=\mathrm{C}\left(1610 \mathrm{~cm}^{-1}\right)$ and $\mathrm{OH}\left(3380 \mathrm{~cm}^{-1}\right)$. These functional groups and their absorption frequencies correspond to that of zeaxanthin (Figure 10). 


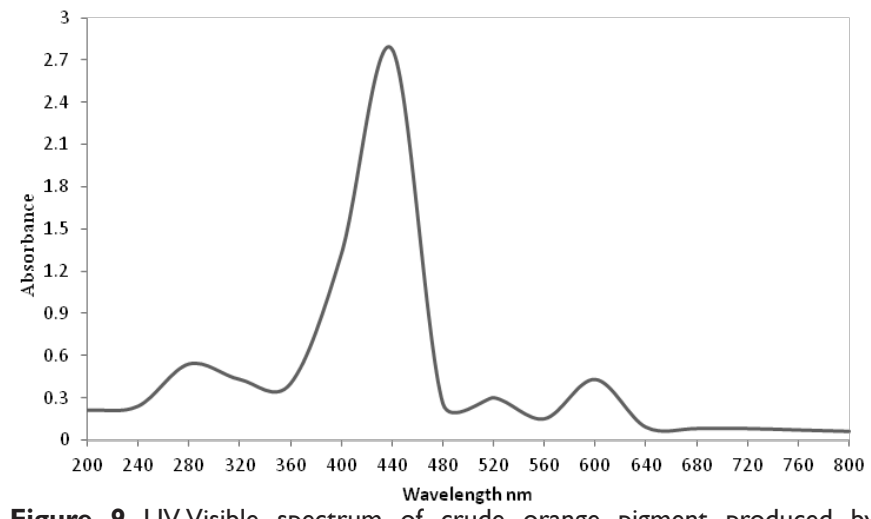

Figure 9 UV-Visible spectrum of crude orange pigment produced by Salinococcus roseus.

The orange pigment showed good stability toward temperature when exposed to $160^{\circ} \mathrm{C}$ and $200^{\circ} \mathrm{C}$ for ten (10) minutes. The reasons for thermal stability of the pigments might be attributed to present of phenolic conjugated double bond in the pigments structure. The thermal stability of pigments implies that the orange pigment can offer various industrial applications such as in dying, textile and food industries. Similar finding by Ahmad et al., ${ }^{7}$ who reported that the pigments produced from bacteria showed good stability toward temperature ranging from $45^{\circ} \mathrm{C}-120^{\circ} \mathrm{C}$ when exposed for one (1) hour (Table 3). The results of pigment stability revealed that the orange pigment changed to different color at $\mathrm{pH} 2$ and 13 . The instability of the pigments at $\mathrm{pH} 2$ and 13 is attributed to complete destruction or alteration of pigments structure at acidic and alkaline $\mathrm{pH}$. In alkaline condition, excess $\mathrm{OH}^{-}$ions from $\mathrm{NaOH}$ deprotonates the phenolic group causing the formation of an anion and destruction in the conjugated structure of the pigment (Table 4$){ }^{7}$

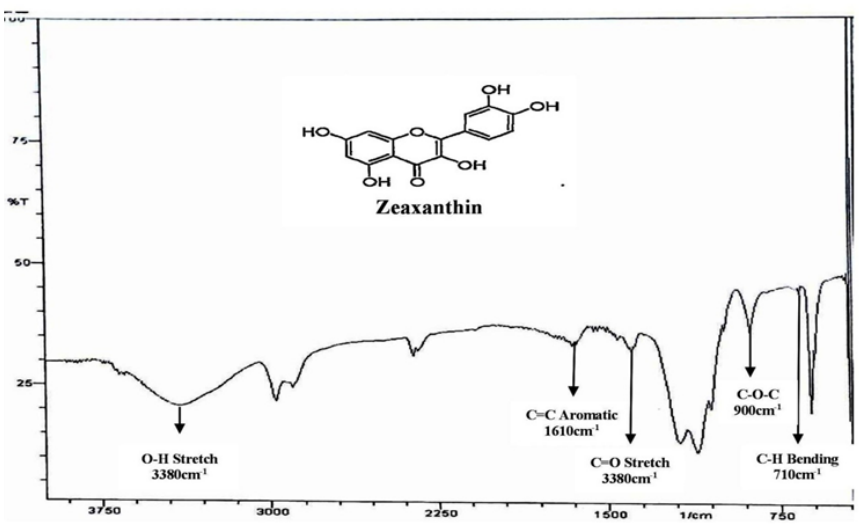

Figure I0 FTIR spectrum of orange pigment produced by Salinococcus roseus.

Table 3 Effect of temperature on stability of the pigments

\begin{tabular}{llll}
\hline Pigments & $\begin{array}{l}\text { Temperature } \\
\text { condition }\end{array}$ & $\begin{array}{l}\text { Maximum } \\
\text { wavelength }\left(\boldsymbol{\Lambda}_{\text {max }}\right)\end{array}$ & $\begin{array}{l}\text { Color } \\
\text { changed }\end{array}$ \\
\hline & Control & $440 \mathrm{~nm}$ & Orange \\
Orange pigment & $160^{\circ} \mathrm{C}$ & $440 \mathrm{~nm}$ & Orange \\
& $200{ }^{\circ} \mathrm{C}$ & $440 \mathrm{~nm}$ & Orange \\
\hline
\end{tabular}

Table 4 Effect of $\mathrm{pH}$ on the stability of pigments

\begin{tabular}{lllll}
\hline Pigment & pH condition & Maximum wavelength (K.max.) & Instant color changed & Color changed after 24 hours \\
\hline \multirow{2}{*}{$\begin{array}{l}\text { Orange } \\
\text { pigment }\end{array}$} & Control 2 & $440 \mathrm{~nm}$ & Orange & Orange \\
& $\mathrm{pH} 13$ & $400 \mathrm{~nm}$ & Yellow & Yellow \\
\end{tabular}

\section{Conclusion}

The results obtained from this study serve as an important insight for production of bio-color from soil inhabiting bacteria. The bacterium was identified as Salinococcus roseus and was to produce orange pigments. The optimization studies revealed that the Salinococcus roseus produced highest orange pigment in nutrient broth, $\mathrm{pH} \mathrm{7}$, at $40^{\circ} \mathrm{C}$ after 96 hours and under shaking condition. The pigment was found stable at temperature of $200^{\circ} \mathrm{C}$ and $\mathrm{pH} 13$. Future studies should focus on elucidating the nature and other application of orange pigment produce by Salinococcus roseus.

\section{Authors' contributions}

This work was carried out in collaboration between all authors. Authors MUH and AAF designed, managed the analysis of the study and wrote the protocol and first draft of the manuscript. Author AN performed the statistical analysis. Authors ASB and GM managed the literature searches. All authors read and approved the final manuscript.

\section{Conflicts of interest}

Authors declare that there are no actual or potential conflicts of interest.

\section{References}

1. Duran N, Teixeira MFS, De Conti R, et al. Ecological-Friendly Pigments from Fungi. Crit Rev Food Sci Nutr. 2002;42(1):53-66.

2. Babu S, Shenolikar IS. Health and Nutritional Implications of Food Colors. Indian J Med Res. 1995;102:245-249.

3. Delgado-Vargas F, Jiménez AR, Paredes-López O. Natural Pigments: Carotenoids, Anthocyanins, and Betalains-Characteristics, Biosynthesis, Processing, and Stability. Crit Rev Food Sci Nutr. 2000;40(3):173-289.

4. Raisainen R, Nousiainen P, Hynninen PH. Dermorubin and 5-chlorodermorubin Natural Anthraquinone Carboxylic Acids as Dyes for Wool. Textile Research Journal. 2002;72(11):973-976.

5. Parekh S, Vinci VA, Strobel RJ. Improvement of Microbial Strains and Fermentation Processes. Appl Microbiol Biotechnol. 2000;54(3):287-301.

6. Venil CK, Lakshmanaperumalsamy P. An Insightful Overview on Microbial pigment: Prodigiosin. Electronic Journal of Biology. 2009;5(3):49-61.

7. Ahmad AS, Ahmad WYW, Zakaria ZK, et al. Applications of Bacterial Pigments as Colorant: the Malaysian perspective. New York: Springer Briefs in Molecular Science. 2012;3(7):57-74. 
8. Cheesbrough M. District Laboratory Practice for Tropical Countries. 2nd edn. UK: Cambridge University Press; 2006. 62-70 p.

9. Altschul SF, Thomas LM, Alejandro AS, et al. Gapped BLAST and PSIBLAST: A New Generation of Protein Database Search Programs. Nucleic Acids Res. 1997;25(17):3389-3402.

10. Bhatt SV, Khan SS, Amin T. Isolation and Characterization of Pigment Producing Bacteria from Various Foods for their Possible Use as Bocolors. International Journal of Recent Scientific Research. 2013;4(10):1605-1609.

11. Slater H, Crow M, Everson L, et al. Phosphate Availability Regulates Biosynthesis of Two Antibiotics, Prodigiosin and Carbapenem in Serratia via Both Quorum Sensing Dependent and Independent Pathways. Mol Microbiol. 2003;47(2):303-320.
12. Zara S. Biosynthesis of Prodigiosin and Its Applications. Journal of Pharmacy and Biological Sciences. 2016;11(6):01-28.

13. Bhat RM, Thankamani Marar. Media Optimization, Extraction and Partial Characterization of an Orange Pigment from Salinicoccus sp. MKJ 997975. International Journal of Life Sciences Biotechnology and Pharma Research. 2015;4(2):85-88.

14. Hejazi A, Falkiner FR. Serratia marcescens. Journal of Medical Microbiology. 1997;46(11):903-912.

15. Kaur B, Chakraborty D, Kaur H. Production and Evaluation of Physicochemical Properties of Red Pigment from Monascus purpures MTCC 410. International Journal of Microbiology. 2009;7(1):215-225.

16. Joshi VK, Attri D, Bala A, et al. Microbial pigments. Indian Journal of Biotechnology. 2003;2:362-369. 